\title{
Ergonomic study of an operator's work of a molybdenum plant
}

\author{
Esteban Oñate ${ }^{\mathrm{a},{ }^{*}}$ and Felipe Meyer ${ }^{\mathrm{a}}$ \\ ${ }^{a}$ Ergonomics Unit, Faculty of Biological Sciences, University of Concepcion, Barrio Universitario s/n, \\ Concepción, Chile.
}

\begin{abstract}
This study was part of an ergonomic program which is being carried out through an agreement between the University of Concepción and a Chilean private mining company. The purpose of this case study was to identify working conditions in which the physical and mental workload could be over the capabilities of the operator. He was responsible for loading trucks with sacks of molybdenum and for downloading reagents and handles them. The methods employed in this study included electronic records, interviews, surveys, review of the company standards, a time study and physical and mental workload analysis. Results showed that $84 \%$ of the time the operator was carrying out principal and secondary activities and no break periods were detected. It was found that the pace of work and the shift system generated unfavorable conditions by imbalance in the workload on the different days of the week. In the light of the results recommendations were made for a number of ergonomic changes. Most of them were accepted by the company. The most important achievement was a change in the shift system. The overload of the operator was due to the fact that he was in a shift working 5 days and resting on weekends. The imbalance was mainly because the work of the week end was accumulated for Monday. As a result of the study, the company contracted a second worker for this job and adopted a $7 \times 7$ shift system, meaning that they work seven days and rest seven days. An evaluation carried out two month after adopting the new shift revealed that changes were well accepted by the worker.
\end{abstract}

Keywords: Working conditions, workload, work study, shift work, organization.

\section{Introduction}

This study was developed in a molybdenum plant of an important mining company in Chile. The operator performed his job five days per week from Monday to Friday, with two day rest on weekends. The worker was responsible for:

- Assembly loads of molybdenum bags.

- Loading trucks with molybdenum bags using a forklift truck.

- To unload chemical reagents from tankers to containers and plastics recipients.

- To handle containers with chemical reagents, with the help of the forklift truck, to be distributed to the interior of the plant.

The study was requested by the company due to the fact that the operator complained because in his perception the demands of work exceeded his capa- bilities. Consequently, the aim of this case study was to identify working conditions in which the physical, mental, environmental and organizational workload could be over the capabilities of the operator.

\section{Material and methods}

Only one worker was doing the job at the time the study started. He was 56 years old and his stature was $172 \mathrm{~cm}$. He had been working 34 years in mining, 14 years in the company and 7 years in the molybdenum plant. He worked in a shift $5 \times 2$, from Monday to Friday from 8:00 hours until 17:30. He had 45 minutes for lunch from 12:30 pm to 13:15 hrs.

The methods employed were the following:

\footnotetext{
*Corresponding author. E-mail: estebanonate@udec.cl
} 


\subsection{Time study}

A continuous time recording was carried out to identify primary and secondary activities, pauses, waiting times, eating times and others.

\subsection{Mental work load}

The NASA-TLX test (Hart and Staveland, 1988) was used to determine the mental workload for each evaluated activity. In addition, results were supplemented by an assessment of psychosocial risks at work, using a questionnaire SUSESO-ISTAS-21 (Alarcón and cols, 2009) in its short version.

\subsection{Organizational factors}

An analysis was made of the activities carried out by the operator, the time required for each activity, the overlap and the possible risks involved.

\subsection{Physical workload}

The physiological workload was assessed through the recording of heart rate with a POLAR system (Polar Vantage, Finland). The electrodes were placed in a belt located in the operator chest and the information was recorded in a clock from where was downloaded for analysis. Cardiac frequency was converted to percentage cardiovascular load (Apud and Meyer, 2002).

Manual material handling $(\mathrm{MMH})$ assessment was carried out after identification of the activities that require it. This was done according to Liberty Mutual (Snook and Ciriello, 1991) and also using the REBA (Rapid Entire Body Assessment) method (Hignett and MacAtammey, 2000). These are the techniques recommended by the Chilean legislation.

\subsection{Environmental factors}

As the work is mostly carried out in open air, thermal load was estimated using the Wet Globe Temperature Humidity (WGTH). For these purpose globe, dry and wet bulb temperature were measured using conventional thermometers.

\section{Results}

\subsection{General working conditions}

Concerning the procedures it is worth highlighting that every morning the operator participated in a program to promote a positive attitude in security. However, it was observed and confirmed by the worker that the filling of its risk assessment form, due to time pressure and the pace of work, could not be done in detail. On the other hand, it was also highlighted, that there is an indication in the procedures stating that the operator has to be present at all times while performing the download of reagents. However, the operator pointed out that this situation was difficult to maintain given the pressure to complete other activities which were also his responsibility. An interview carried out to analyze this issue and others related to the perception of the operator about the demands of work, showed the following results:

- The worker considered that due to the shift system there was accumulation of work during weekends, when he was resting. For this reason, he stressed that the amount of work and effort was much higher on Monday.

- He also pointed out that time pressure to finish the tasks was constant. His perception was that there was more work during the afternoon than during the morning. This was due to the fact that he had to close the shift without leaving uncompleted tasks.

\subsection{Time study}

The time study and the classification of the type of activities carried out by the operator during the four days of evaluation, showed that the time required for main and secondary activities reached $84 \%$. In addition, no periods of rest during the development of the various tasks were observed. Table 1 summarizes the types of activities and the time devoted to them for the days evaluated.

It is important to mention that principal activities that require more time were assembly of lots and handling of containers with the use of forklift. In the case of secondary activities the longer time were found when the worker was preparing himself for a new task, when he was moving within the plant in his vehicle and when he was doing administrative work. On the other hand the average time for lunch was 54 minutes per day. 
Table 1

Type of activities and time devoted to them during four days of evaluation

\begin{tabular}{|l|c|c|}
\hline \multicolumn{1}{|c|}{ Type of activity } & Time (min) & \% of total time \\
\hline Principal & 921 & 55.0 \\
\hline Secondary & 486 & 29.0 \\
\hline Lunch & 221 & 13.2 \\
\hline Other & 3 & 0.2 \\
\hline Pause & 0 & 0.0 \\
\hline Physiological needs & 11 & 0.7 \\
\hline Waiting time & 32 & 1.9 \\
\hline TOTAL & 1674 & 100.0 \\
\hline
\end{tabular}

\subsection{Mental workload}

In the light of the evaluation on conditions of work and the perception that the operator had about the demands of his activities, it was necessary to obtain objective data enabling to estimate the mental load which was evaluated using the NASA-TLX (Hart and Staveland, 1988) test. Table 2 summarizes the general information.

Table 2

General results of the of the NASA-TLX test.

\begin{tabular}{|l|c|c|c|c|}
\hline \multicolumn{1}{|c|}{ Variable } & $\begin{array}{c}\text { Mean } \\
\text { value }\end{array}$ & Minimum & Maximum & S.D. \\
\hline Effort & 412.5 & 270.0 & 500.0 & 65.8 \\
\hline $\begin{array}{l}\text { Physical } \\
\text { demands }\end{array}$ & 353.4 & 270.0 & 450.0 & 58.3 \\
\hline $\begin{array}{l}\text { Temporary } \\
\text { demands }\end{array}$ & 346.9 & 270.0 & 475.0 & 54.9 \\
\hline $\begin{array}{l}\text { Mental } \\
\text { demands }\end{array}$ & 79.7 & 0.0 & 180.0 & 45.3 \\
\hline Performance & 40.6 & 0.0 & 195.0 & 46.1 \\
\hline Frustration & 14.4 & 0.0 & 70.0 & 26.6 \\
\hline
\end{tabular}

With the aim of establishing the degree of impact of these variables in the mental health of the worker, the test of psychosocial risk factors SUSESO-ISTAS 21 brief version (Alarcón and cols, 2009) was applied. This is the official test proposed by the Chilean Ministry of Labour and Social Welfare.

The results observed in table 3 showed that the operator was in a high level of psychosocial risk in four of the five items.

Results showed that the operator had a high mental load determined by his perception of being subject to physically demanding effort and time pressure to the limit of its capabilities. At the same time, psychosocial risks exposure levels were high, as compared to standards for the Chilean population.
Table 3

Summary of the evaluation of psychosocial occupational SUSESO-ISTAS 21 version risk factors shortly.

\begin{tabular}{|l|c|c|c|}
\hline \multicolumn{1}{|c|}{$\begin{array}{c}\text { Psychosocial } \\
\text { dimension }\end{array}$} & Score & High level & Category \\
\hline $\begin{array}{l}\text { 1.Psychological } \\
\text { demands }\end{array}$ & 14 & From 12 to 20 & High level \\
\hline $\begin{array}{l}\text { 2 Active work and } \\
\text { skills development }\end{array}$ & 10 & From 9 to 20 & High level \\
\hline $\begin{array}{l}\text { 3. Social support in } \\
\text { company }\end{array}$ & 6 & From 7 to 20 & Medium level \\
\hline 4 Compensation & 6 & From 6 to 12 & High level \\
\hline 5 Double presence & 4 & From 4 To 8 & High level \\
\hline
\end{tabular}

\subsection{Organizational factor}

As mentioned before, principal and secondary activities altogether occupied $84,0 \%$ of the shift. It is important to notice that the worker had no rest pauses, except for lunch.

The work load derived from the organization of work, was evaluated by determining if there was enough time to perform the tasks normally. In other words, it was observed if the worker could cope with the procedures established by the enterprise and the specific requirements of the tasks. Special emphasis was put on situations that generated delays and on the development of activities parallel to the discharge of chemical reagents.

On the last point, it should be noted that the operator must monitor the activities at all times according to standard procedures adopted by the enterprise. He should be permanently aware in case of spill, break of duct or any other event that should be quickly solved. Any incident, had operational implications and risks for the safety of workers and for the production. This can also mean a delay in operations and burns because of the corrosive effect of these chemicals products. Under extreme conditions, they may have fatal consequences in case that sulfhidric gas is formed.

To establish whether the organizational demands were not over the capabilities of the operator, the time required to develop the tasks at normal speed were observed. Special consideration was given to the time needed to carry out parallel activities to the discharge of reagents. Table 4 summarizes the type of activities that were carried out in parallel. The table shows in detail, the minutes that the worker did not monitor the discharge of chemicals because he was doing other jobs. 
Table 4

Activities in parallel to the discharge of reagents and minutes without supervision of this activity because the worker was carrying out other tasks.

\begin{tabular}{|l|c|}
\hline \multicolumn{1}{|c|}{ Activities } & Minutes (min) \\
\hline $\begin{array}{l}\text { Operator goes and returns from cellar during } \\
\text { the period devoted to the download of } \\
\text { chemicals }\end{array}$ & 4 \\
\hline $\begin{array}{l}\text { Operator assemble lots of molybdenum } \\
\text { while unloading chemicals }\end{array}$ & 12 \\
\hline $\begin{array}{l}\text { Operator prepares to download chemicals } \\
\text { while the truck driver connected hoses for } \\
\text { download. }\end{array}$ & 18 \\
\hline $\begin{array}{l}\text { Operator is in the office, fixing a problem } \\
\text { with the key of the computer }\end{array}$ & 7 \\
\hline $\begin{array}{l}\text { Operator is in the office filling forms of risk } \\
\text { assessment }\end{array}$ & 18 \\
\hline Operator goes to the toilet & 100 \\
\hline Operator move container to the plant & 5 \\
\hline TOTAL & \\
\hline
\end{tabular}

These activities were carried out by the operator because it was the only way to complete the tasks during the shift.

\subsection{Physical workload}

Table 5 summarizes the results for the cardiovascular load during the total time evaluated and also for each separate day of study. As it can be observed, in any day, the cardiovascular load exceeded 40 per cent on average, which is the limit considered in Chile to legally qualify a job as heavy work. However, it should be noticed that the recommended limit and the average value, for the first day of the week evaluated, were very close.

Table 5

Percentage cardiovascular measured during different days of the week.

\begin{tabular}{|l|c|c|c|c|}
\hline $\begin{array}{c}\text { Day of the } \\
\text { week }\end{array}$ & $\begin{array}{c}\text { Minutes } \\
\text { evaluated }\end{array}$ & $\begin{array}{c}\text { \% Total } \\
\text { time }\end{array}$ & $\begin{array}{c}\text { Mean } \\
\text { value }\end{array}$ & D.E. \\
\hline Monday & 485 & 29.0 & 38.3 & 7.4 \\
\hline Tuesday & 273 & 16.3 & 35.8 & 7.6 \\
\hline Wednesday & 468 & 28.0 & 32.4 & 8.5 \\
\hline Thursday & 448 & 26.8 & 32.7 & 7.0 \\
\hline TOTAL & 1674 & 100.0 & 34.8 & 8.1 \\
\hline
\end{tabular}

On the other hand, it is important to analyze the behavior of the cardiovascular load in the morning and the afternoon on the day more critical that was Monday. The results are summarized in table 6, which also shows the number of activities carried out in the morning and evening. The table shows that in the afternoon, the work exceeds recommended limits of physiological load reaching a mean value for cardiovascular load of $41.3 \%$.

Table 6

Cardiovascular load in the morning and afternoon of the most critical day.

\begin{tabular}{|c|c|c|c|c|}
\hline $\begin{array}{c}\text { Time of } \\
\text { the day }\end{array}$ & $\begin{array}{c}\text { Time } \\
\text { (min) }\end{array}$ & $\begin{array}{c}\text { Number } \\
\text { of } \\
\text { activities } \\
\text { carried } \\
\text { out }\end{array}$ & $\begin{array}{c}\text { Number of } \\
\text { activities } \\
\text { per hour }\end{array}$ & $\begin{array}{c}\text { M. C.C. } \\
\text { Mean } \\
\text { value }\end{array}$ \\
\hline Morning & 227 & 25 & 6.6 & 35.0 \\
\hline Afternoon & 258 & 43 & 10.0 & 41.3 \\
\hline
\end{tabular}

\subsection{Manual material handling}

The operator carried out two types of activities requiring manual effort. These were manual handling of empty containers and replacement of other containers full with chemicals. The activities are illustrated in Figure 1.

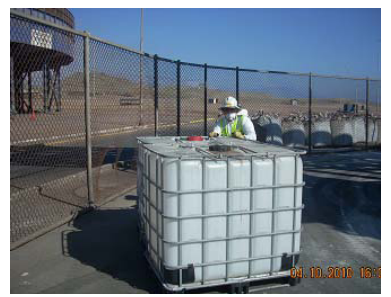

Manual handling of empty containers

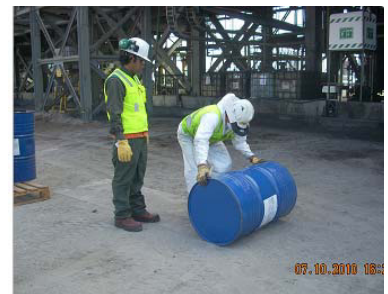

Manual handling of full containers
Figure 1. Activities that require manual handling of materials

Regarding the manual handling of empty containers it should be noted that these are containers of polyethylene, which are protected by a metal mesh, have a height of $130 \mathrm{~cm}$ and a weight of $65 \mathrm{Kg}$. However, even in the worst case the movement was slight, only to accommodate them, to be mobilized by the forklift. The number of attempts in the worst case was 23 times per day and the force required to begin the movement reached $26 \mathrm{Kg}$. It is important to point out that the manual handling was due to the fact that the containers were not properly placed.

In relation to the replacement of full containers, part of this activity was carried out by the forklift and the other executed manually. It was noted that in one of the procedures the operator should turn the container of roughly $230 \mathrm{Kg}$ and spin it. It was observed that when carrying out this manual handling task the 
operator did it flexing his body, twisting the trunk and elevating the shoulders. He also applied force abruptly requiring significant postural changes.

Calculations were made according to the Chilean legislation related to the maximum load for human handling. Considering that the movement of the empty container demands pushing the load and that the movement of the full container is a complex activity, which requires changes of posture, different methods were used to evaluate both tasks. These techniques were the Liberty Mutual Tables (Snook y Ciriello, 1991) and REBA (Rapid Entire Body Assessment) (Hignett y MacAtammey, 2000), respectively. The results obtained for the manual handling of the empty containers are summarized in table 7 while those for the full container are shown in table 8 .

Table 7

Manual handling of empty containers. Results obtained from the tables of the Liberty Mutual.

\begin{tabular}{|c|c|c|c|c|}
\hline $\begin{array}{c}\text { Section } \\
\text { height } \\
(\mathrm{cm})\end{array}$ & $\begin{array}{c}\text { Percentage } \\
\text { population } \\
\text { covered }\end{array}$ & $\begin{array}{c}\text { Frequency } \\
\text { section } \\
(\mathrm{min})\end{array}$ & $\begin{array}{c}\text { Initial } \\
\text { Force } \\
(\mathrm{kg})\end{array}$ & $\begin{array}{c}\text { Maximum } \\
\text { Acceptable } \\
\text { Force }(\mathrm{kg})\end{array}$ \\
\hline $144-95$ & 90 & $5-30$ & 26 & 26 \\
\hline
\end{tabular}

Table 7 contains the information needed to calculate the maximum acceptable force for the activity of manual handling of empty containers. The result indicates that the force developed by the operator to handle this type of containers was equal to the maximum acceptable. Therefore this activity lies in the limit to be considered a risk for the development of muscle-skeletal disease.

Table 8 shows the results for the manual handling of full containers according to the REBA method. The results show that there is a high risk of skeletal muscle disease.

Table 8

Results for the evaluation of manual handling of full containers according to the REBA method

\begin{tabular}{|c|c|}
\hline $\begin{array}{c}\text { Score for the segment neck, trunk and legs }+ \\
\text { load and strength }\end{array}$ & 11 \\
\hline $\begin{array}{c}\text { Score for the segment arm, forearm and wrist } \\
+ \text { load coupling }\end{array}$ & 6 \\
\hline $\begin{array}{c}\text { Score for the segment arm, forearm and wrist } \\
+ \text { load coupling }\end{array}$ & 13 \\
\hline Final Score REBA & High \\
\hline Level of risk for skeletal muscle disease & Immediate \\
\hline Level of action & \\
\hline
\end{tabular}

\subsection{Environmental factors.}

Table 9 shows the results for the measurement of the thermal environment. As it can be seen the WGTH index s within acceptable limits

\begin{tabular}{|c|c|c|c|}
\hline Variable & $\begin{array}{c}\text { Minutos de } \\
\text { Evaluación }\end{array}$ & Promedio & D.E. \\
\hline WGTH $\left({ }^{\circ} \mathrm{C}\right)$ & 328 & 18,2 & 1,9 \\
\hline
\end{tabular}

\section{Conclusions and recommendations}

The operator followed the majority of the established procedures. He participated in a program to promote a positive attitude in security and he also complete a form entitled "risk assessment of work". However, due to pressure of time and pace of work he may not carry out this latter process with the required details. On the other hand, even when he must remain all the time in the area of download of reagents while performing this procedure, he is unable to do so due to the need to complete other tasks on time.

$84 \%$ of the time evaluated the operator was conducting principal and secondary activities. In addition, no scheduled neither non scheduled breaks were recorded. These data indicate that the operator had high work load which does not allow the tasks to be developed normally, situation that is corroborated by mental load tests. Complementary to this, it was concluded that the operator was exposed to an unfavourable psychosocial condition which may be a risk for his health.

From the study, it was concluded that the organization of work made it necessary for the operator to carry out parallel activities when he had to be supervising the handling of chemicals. Even so, there were circumstances which effectively delayed the work. Therefore, both situations indicate the need for changes in the working system to add additional time. It was estimated that the operator required at least an hour of extra time per day to finish his tasks normally.

The results showed that the operator received a high burden of work on Monday. This can be seen by the high number of parallel activities and the physiological work load for that day. The reason was the accumulation of work, because no one was doing the job over the week end.

The results allowed to recommend a change in the shift system from 2 X 5 to 7 X 7 with the incorpora- 
tion of a second operator for the same work. This recommendation was accepted and implemented by the company. Evaluations carried out two months after the changes were implemented demonstrated a reduction in the workload due to the reduction of parallel activities and because no work was accumulated over the weekend. The interviews with the worker, the assessment of mental workload and the evaluation of exposure to psychosocial risk factors, showed positive changes and a good perception of the worker with regard to the innovations.

Finally, it was detected that manual handling of containers requires the use of force at a level which is just in the limit of maximum acceptable force. This was particularly critical for the handling of full containers, activity that involves a high risk of musculo skeletal disorders requiring a prompt solution. This is being faced through a participatory program which includes training and the analysis with managers and workers of better technological alternatives to carry out the manual handling of material in the whole enterprise.

\section{References}

[1] E. Apud and F. Meyer. Ergonomía para la Industria Minera. Primera Edición. Concepción: Universidad de Concepción (2009), $538 \mathrm{p}$.

[2] G. Kanawaty. Introducción al estudio del Trabajo. Cuarta Edición. Ginebra: Organización Internacional del Trabajo (1996) .525p

[3] M. Connors. NASA-TLX (Nacional Aeronautics and Space Administration - Task Load Index) (1986).<http://humanfactors.arc.nasa.gov/groups/TLX/downlo ads/TLX.pdf>.

[4] A. Soto, SUSESO-ISTAS 21 Manual de Uso (2009) $<$ http://163.247.55.35/cuestion.nsf $>$.

[5] Decreto Supremo $\mathrm{N}^{\circ} 63$ (2005) aprueba reglamento para la aplicación de la Ley $\mathrm{N}^{\circ} 20.001$ que regula el peso máximo de carga humana, de 27 de julio, del Estado de Chile. Biblioteca del Congreso Nacional

[6] Ley $\mathrm{N}^{\circ} 20.001$ (2005) regula el peso máximo de carga humana, del 28 de enero, del Estado de Chile. Bibliotheca del Congreso Nacional.

[7] Guía Técnica para la evaluación y control de los riesgos asociados al manejo o manipulación manual de carga (2008). Subsecretaría de Previsión Social. Santiago: Ministerio del Trabajo y Previsión Social. 